\title{
Influence of action potential onset rapidness to dynamic response of cortical neurons W Wei ${ }^{1,2,3}$ and F Wolf*1,2,3
}

\author{
Address: ${ }^{1}$ Department of Nonlinear Dynamics, Max-Planck-Institute for Dynamics and Self-Organization, D37073Göttingen, Germany, \\ ${ }^{2}$ Bernstein Center for Computational Neuroscience, D37073 Göttingen, Germany and 3Faculty of Physics, University of Göttingen, D37073 \\ Göttingen, Germany \\ Email: FWolf* - fred@nld.ds.mpg.de \\ * Corresponding author
}

from Eighteenth Annual Computational Neuroscience Meeting: CNS*2009

Berlin, Germany. 18-23 July 2009

Published: 13 July 2009

BMC Neuroscience 2009, I0(SuppI I):P327 doi:10.1186/I47I-2202-I0-SI-P327

This abstract is available from: http://www.biomedcentral.com/I47I-2202// 0/SI/P327

(c) 2009 Wei and Wolf; licensee BioMed Central Ltd.

\section{Introduction}

Neurons can track fast signal through population coding.In principle, there are two separate channels for signal encoding, the mean synaptic current and the amplitude of synaptic noise. Experiments indicate that ensembles of cortical neurons behave like a low-passed filter with a high cut-off frequency and that the response speed for noise coded signal is much faster than that for mean current coded signal [1-3]. It has been shown numerically that details of action potential (AP) generation mechanism of single neurons play an important role in the dynamical response of neuronal populations $[4,5]$.We constructed a new dynamic model of AP generation in which the onset rapidness $r$ of AP initiation is a freely var-
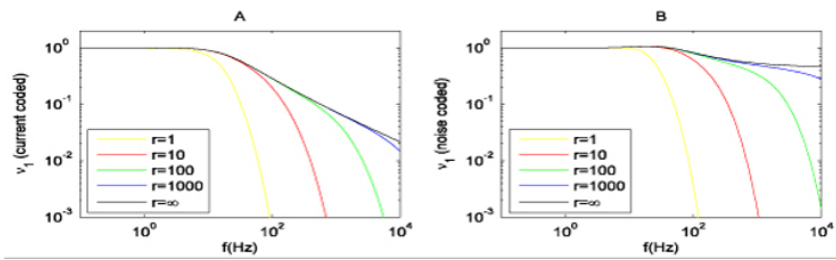

Figure I

The normalized transmission functions for mean current coded signal $(A)$ and noise coded signal (B) with firing rate at $5 \mathrm{~Hz}$. The different curves are for $r=1,10$, 100, 1000 and infinity (LIF) respectively. iable parameter and which is analytical solvable. The $r-\tau$ model reduces to the leaky integrate and fire model (LIF) for infinite $r$ and to the perfect integrator model for zero $r$. For finite $r$ the impact of dynamic AP generation for linear response is accessible to rigorous analysis. We find that the linear response decomposes into two parts: one part approaches zero when the absorbing boundary is moved to infinity, indicating an artifact of the model; the other part possesses only a weak dependence on the boundary and reproduces the results for LIF neurons for $r \rightarrow \infty$. This part reflects the dynamics of AP generation. We find that when the onset rapidness is large, the cut-off frequency for noise coded signal will be proportional to the onset rapidness, while for mean current coded signal it is constrained by the membrane time constant (Fig. 1). Since the onset rapidness of APs was found experimentally to be very large [6], our model explained why the response speed can be much faster for variance coded signal than for mean current coded signal.

\section{References}

I. Silberberg G, Bethge M, Markram H, Pawelzik K, Tsodyks M: Dynamics of population rate codes in ensembles of neocortical neurons. J Neurophysiol 2004, 9 1:704-709.

2. Köndgen H, Geisler C, Fusi S, Wang XJ, Lüscher HR, Giugliano M: The dynamical response properties of neocortical neurons to temporally modulated noisy inputs in vitro. Cereb Cortex 2008, I 8:2086-2097.

3. Boucsein C, Tetzlaff T, Meier R, Aertsen A, Naundorf B: Dynamical response properties of neocortical neuron ensembles: multiplicative versus additive noise. J Neurosci 2009, 29:1006-1010. 
4. Fourcaud-Trocmé N, Hansel D, van Vreeswijk C, Brunel N: How spike generation mechanisms determine the neuronal response to fluctuating inputs. J Neurosci 2003, 23: I I628-I I640.

5. Naundorf B, Geisel T, Wolf F: Action potential onset dynamics and the response speed of neuronal populations. I Comput Neurosci 2005, 18:297-309.

6. Naundorf B, Wolf F, Volgushev M: Unique features of action potential initiation in cortical neurons. Nature 2006, 440: $1060-1063$.

Publish with Bio Med Central and every scientist can read your work free of charge

"BioMed Central will be the most significant development for disseminating the results of biomedical research in our lifetime. "

Sir Paul Nurse, Cancer Research UK

Your research papers will be:

- available free of charge to the entire biomedical community

- peer reviewed and published immediately upon acceptance

- cited in PubMed and archived on PubMed Central

- yours - you keep the copyright

Submit your manuscript here:

http://www.biomedcentral.com/info/publishing_adv.asp 